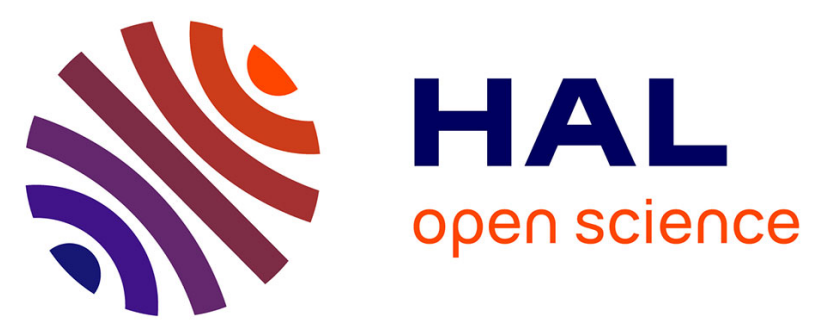

\title{
Chest low-dose computed tomography for early lung cancer diagnosis as an opportunity to diagnose vertebral fractures in HIV-infected smokers, an ANRS EP48 HIV CHEST substudy
}

Yann Thouvenin, Alain Makinson, Amandine Cournil, Sabrina

Eymard-Duvernay, Pierre Lentz, Anne-Sophie Delemazure, Olivier Corneloup, Sylvie Fabre, Mylène Quesnoy, Sylvain Poire, et al.

\section{- To cite this version:}

Yann Thouvenin, Alain Makinson, Amandine Cournil, Sabrina Eymard-Duvernay, Pierre Lentz, et al.. Chest low-dose computed tomography for early lung cancer diagnosis as an opportunity to diagnose vertebral fractures in HIV-infected smokers, an ANRS EP48 HIV CHEST substudy. Journal of Acquired Immune Deficiency Syndromes - JAIDS, 2015, 69 (3), pp.299-305. 10.1097/QAI.0000000000000599 . hal-01987720

\author{
HAL Id: hal-01987720 \\ https://hal.science/hal-01987720
}

Submitted on 21 Jan 2019

HAL is a multi-disciplinary open access archive for the deposit and dissemination of scientific research documents, whether they are published or not. The documents may come from teaching and research institutions in France or abroad, or from public or private research centers.
L'archive ouverte pluridisciplinaire HAL, est destinée au dépôt et à la diffusion de documents scientifiques de niveau recherche, publiés ou non, émanant des établissements d'enseignement et de recherche français ou étrangers, des laboratoires publics ou privés. 


\title{
Chest Low-Dose Computed Tomography for Early Lung Cancer Diagnosis as an Opportunity to Diagnose Vertebral Fractures in HIV-Infected Smokers, an ANRS EP48 HIV CHEST Substudy
}

\author{
Yann Thouvenin, MD, ${ }^{*}$ Alain Makinson, MD, $\dagger \ddagger \S$ Amandine Cournil, PhD $\ddagger$ \\ Sabrina Eymard-Duvernay, MSc, $\ddagger$ Pierre Lentz, MD,k Anne-Sophie Delemazure, MD, \\ Olivier Corneloup, MD,\# Sylvie Fabre, MD, PhD,§ Mylène Quesnoy, MSc, $\ddagger$ Sylvain Poire, MD, ** \\ Pierre-Yves Brillet, MD, $\uparrow \dagger$ Catherine Cyteval,MD, PhD, ${ }^{*}$ Jacques Reynes, MD, PhD, $\dagger \ddagger$ and \\ Vincent Le Moing, MD, PhD $\uparrow \neq$ the ANRS HIV CHEST Study Team
}

Background: To estimate the prevalence of vertebralfractures on chest low-dose computed tomography (LDCT) in HIV-infected smokers.

Methods: Cross-sectionalstudy of vertebralfractures visualized on chest LDCT from a multicenter prospective cohort evaluating feasibility of chest LDCT for early lung cancer diagnosis in HIV-infected subjects. Subjects were included if 40 years or olderhad been active smokers within the last 3 years of at least 20 pack-years, and had a CD4 T-lymphocyte nadir cell count ,350 per microliter and an actual CD4 T-cell count .100 cells per microliter. Spinal reconstructed sagittal planes obtained from chest axial native acquisitions were blindly read by a musculoskeletalimaging specialist.Assessment of the fractured vertebra used Genantsemiquantitative methodThe study end point was the prevalence of at least 1 vertebral fracture.

Results: Three hundred ninety-seven subjects were included. Median age was 49.5 years, median smoking history was 30 pack-years, median last CD4 count was 584 cells per microliter, and median CD4 nadir count was 168 cells per microliter; $90 \%$ of subjects had a viral load below 50 copies per milliliter. At least 1 fracture was visible in 46 $(11.6 \%)$ subjects. In multivariate analysis, smoking $\$ 40$ packs-years

Received for publication October 1, 2014; accepted January 27, 2015.

From the * Department of Medical Imaging, Lapeyronie Hospital, University Montpellier, Montpellier, France; †Department of Infectious and Tropical Diseases, University Montpellier, Montpellier, France; $†$ UMI 233, IRD, University Montpellier, Montpellier, France; §Department of Internal Medicine, Clinique Beau-Soleil, Montpellier, France; kDepartment of Medical Imaging, University Hospital Pontchaillou, Rennes, France; qDepartment of Medical Imaging, University hospital Hôtel Dieu, Nantes, France; \#Department of Medical Imaging, University Hospital Haut Lévèque, Bordeaux, France; ${ }^{* *}$ Department of Medical Imaging, University Hospital Necker-Enfants Malades, Paris, France; and ††UPRES EA 2363, Sorbonne Paris Cité, University Paris 13; Department of Medical Imaging, University Hospital Avicenne, Bobigny, France.

Supported by l'Agence nationale de recherches sur le sida et les hépatites virales, agence autonome de l'INSERM (ANRS).

The authors have no conflicts of interest to disclose.

Y.T. and A.M. contributed equally to the study.

Correspondence to: Alain Makinson, MD, UMI 233, IRD, Department of Infectious and Tropical Diseases, University Montpellier, Montpellier, France (e-mail: a-makinson@chu-montpellier.fr).

Copyright $\odot 2015$ Wolters Kluwer Health, Inc. All rights reserved.
[OR $=2.5 ; 95 \% \mathrm{Cl}:(1.2$ to 5.0$)]$ was associated with an increased risk of vertebral fracture,while HIV viral load ,200 copies per milliliter $[\mathrm{OR}=0.3 ; 95 \% \mathrm{Cl}:(0.1$ to 0.9$)]$ was protective.

Conclusions: Prevalence of vertebral fractures on chest LDCT was $11.6 \%$ in this high-risk population. Smoking cessation and early introduction of antiretroviral therapy for prevention of vertebral fractures could be beneficial. Chest LDCT is an opportunity to diagnose vertebral fractures.

Key Words: HIV, vertebral fracture, osteoporosis, computed tomography, smoking, lung cancer

(J Acquir Immune Defic Syndr 2015;69:299-305)

\section{INTRODUCTION}

Osteoporosis is a condition characterized by low bone mass and microarchitectural deterioration of bone tissue leading to enhanced bone fragility and a consequent increase in fracture risk. Low-trauma vertebral fractures have been associated in the elderly with an increased standardized mortality rate and with incident secondary fractures, ${ }^{1,2}$ chronic dorsalgia, ${ }^{3}$ height loss, ${ }^{3}$ kyphosis, ${ }^{3}$ reduced lung function capacity, chronic obstructive pulmonary disease, ${ }^{4,5}$ and diminished quality of life. ${ }^{6}$ Prevalence of osteoporosis and fractures is high in people living with HIV, 7 increased in comparison with their HIV-uninfected counterparts.? In the women's menopause study, low bone mineral density (BMD) was $27 \%$ among HIV-positive versus $19 \%(P=0.04)$ in HIVuninfected women, ${ }^{8}$ and in a nationwide Danish study of 124,655 fracture cases and 373,962 age- and gender-matched controls, the risk of any fracture was significantly increased among HIV-infected patients $(\mathrm{OR}=2.89)$. ${ }^{9}$

HIV-related factors associated with osteoporosis include tenofovir disoproxyl fumarate (TDF) use, ${ }^{10-13}$ protease inhibitor use, ${ }^{10,14}$ low CD4 level, ${ }^{15}$ and HIV replication. ${ }^{16}$ Among HIV-unrelated factors, white race ${ }^{10}$ increasing age, ${ }^{7,8,10}$ decreased body mass index or weight $, 8,10,17$ hepatitis $\mathrm{C}$ virus (HCV) coinfection, ${ }^{10}$ estrogen use, ${ }^{8}$ corticoid use,${ }^{15}$ or previous fractures ${ }^{8}$ have been reported in the HIV-infected 


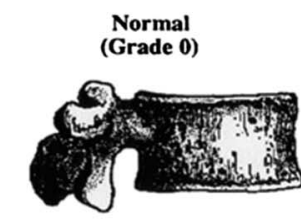

Wedge deformity
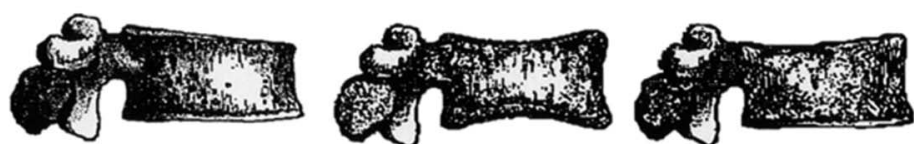

Moderate deformity (Grade 2)
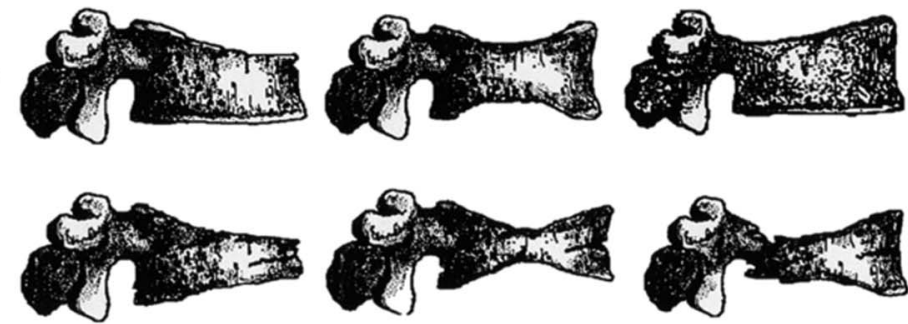

FIGURE 1. Genant semiquantitative method developed by Genant et al ${ }^{25}$ on conventional radiography. Reproduced with permission from the author. ${ }^{24}$
Severe deformity (Grade 3)
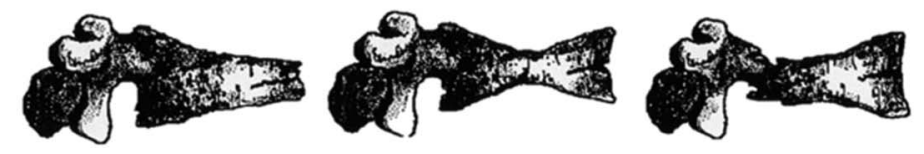

population. Alcohol intoxication, ethnic origin, femoral fracture family history, menopause, testosterone insufficiency, sedentary life, vitamin $\mathrm{D}$, and calcium insufficiencies are probably important risk factors in the HIV-infected as they are in the general population. Smoking has been associated with BMD loss and osteoporosis in the genera ${ }^{\mathrm{A}}, 18,19$ and the HIVinfected ${ }^{10}$ population.

Most studies dealing with osteopenia and osteoporosis in HIV-infected patients are based on surrogate evaluation of BMD with dual-energy $x$-ray absorptiometry (DXA) scans and rarely estimate the presence of bone fractures, despite the fact that fractures are the main clinically significant consequence of osteoporosis. Also, DXA scan is an unreliable method to screen for osteoporotic fractures. The presence of 1 or more low-impact fragility fractures (ie, on a spinal radiograph) is considered as a sign of severe osteoporosis, even in the absence of osteoporotic BMD. ${ }^{20}$ Also, studies in the general population have found that the risk of new vertebral fractures increased with the diagnosis of a prevalent fracture, furthermore underscoring the importance of initiating osteoporosis treatment when fractures are detecte?l.

In the context of osteoporosis, vertebral fractures are commonly undiagnosed and clinically silent. ${ }^{22}$ The use of imaging for other reasons is thus an opportunity to detect fractures, as with the use of chest low-dose computed tomography (LDCT) screening of high-risk subjects for lung cancer. ${ }^{23}$ This applies particularly well to the HIV-infected smoking populations, in which several risk factors of osteoporosis coexist. We sought to estimate the prevalence of vertebral fractures in a cohort of HIV-infected smokers participating in an early lung cancer diagnosis study with chest LDCT.

\section{METHODS}

\section{Study Population and Settings}

This is a cross-sectional post hoc study of vertebral fractures visualized on chest LDCT after sagittal spinal reconstruction in subjects included in the ANRS EP48 HIV CHEST cohort, a multicenter ongoing prospective study evaluating feasibility of chest LDCT for early lung cancer diagnosis in HIV-infected subjects in France (clinical trials registration number: NCT01207986). Subjects included had to be 40 years or older, had a history of smoking within the last 3 years of at least 20 pack-years, had a CD4 T-lymphocyte nadir cell count ,350 per microliter and an actual CD4 T-cell count .100 cells per microliter, and had medical coverage. Subjects were excluded in case of active cancer or active AIDS-classifying disease, lung infection within 2 months, pregnancy, breast-feeding, evident contraindication to thoracic surgery, and suspicion of malignant vertebral fracture. All subjects were proposed to participate in the study during their quarterly or biannual visit with their HIV specialist, and subjects signed an informed consent.Subjects were included between March 2011 and June 2012. The study sponsor was the ANRS, and the study was approved by the Institutional Review Board "Comité de Protection des Personnes Sud Méditerranée IV" on May 11, 2011. Study procedures were in accordance with the standards of Ethics Committee and with the Helsinki Declaration.

\section{CT Reconstruction Methods and Vertebral Fracture Diagnosis}

Acquisition procedures of chest LDCT in the early lung cancer screening study were the following: the entire chest from apex to posterior recesses was included at end inspiration in 1 breath hold according to the low-dose protocol of the study $(100 \mathrm{kVp}$, automated tube current modulation) with section thickness not greater than $1 \mathrm{~mm}$. However, procedures were adapted in each center according to the scanning equipment. The median dose-length product for the chest LDCT was $212 \mathrm{mGy} \$ \mathrm{~cm}$, (IQR 142-312) corresponding to a median effective dose of $3.8 \mathrm{mSv}$ IQR (2.6-5.6), considering an effective dose per unit dose-length 
product conversion factor of $0.018 \mathrm{mSv} .{ }^{24}$ No phantom had been used in this study. Reconstructed sagittalplanes of the spine were obtained from the axial native acquisition of the chest, after the images were centralized in the Radiology Department of the University Hospital of Montpellier. A 6-year experienced radiologist (YT) specialized in musculoskeletal imaging blindly reviewed the reconstructed sagittal spinal images. The radiologist recorded the first and last totally visible vertebral body and the number and location of fractured vertebras. Assessment of the fractured vertebra used the recognized semiquantitative method developed by Genant and his colleagues on conventional radiography (Fig. 1). ${ }^{25}$ Briefly, visible vertebras were graded as mildly deformed (grade 1, approximately $20 \%-25 \%$ in anterior, middle, and/or posterior height and a reduction of area of $10 \%-20 \%$ ), moderately deformed (grade 2, approximately $25 \%-40 \%$ in any height and a reduction of area of $20 \%-40 \%$ ), and severely deformed (grade 3, approximately $40 \%$ in any height and area). A vertebra was considered fractured if graded 1 or more. The shape of the fractures was described as crushed, wedged, or biconcave accordingly. Genant semiquantitative method has previously shown intra- and interobserver reliability and agreement on chest computed tomographæ̌.

\section{Statistical Analysis}

The end point of our study was the prevalence of at least 1 vertebral fracture. Variables tested for association with the outcome were age, sex, low body mass index, $18.5 \mathrm{~kg} / \mathrm{m} 2$ (WHO definition of underweight), smoking history (\$40 packyears), cannabis inhalation history and alcohol intoxication (as appreciated by the investigator as Yes/No variables), presence of hepatitis C (as defined by a positive serology), history of intravenous drug use, last HIV viral load ,200 copies per milliliter (thus allowing for blips), last level of CD4 T-lymphocytes, nadir level of CD4,200 cells per microliter, duration of antiretroviral therapy (ART), duration of TDF therapy and actual TDF use. Ethnic origin was unavailable, as was known history of osteoporosis, vertebral fracture, or trauma. Age was analyzed in 4 categories (40-44 years, 45-49 years, 50 to 54 , and older than 55 years). Each variable was tested separately using a generalized linear mixed model including center as a random effect.Variables retained in the multivariable analysis were those with a $\mathrm{P}$ value for association with vertebral fracture below 0.20. Stata (version 12.1; Stata Corp, College Station, TX) statistical software was used for the analyses.

\section{RESULTS}

Of the 443 subjects with a LDCT enrolled in the HIV CHEST study, 397 subjects had a chest LDCT with sagittal spinal reconstruction planesThus, 46 subjects could not have their LDCT reconstructed, 17 because their CT images had not been centralized in the Radiology Department of the Montpellier University Hospital (eg, images not sent), and 29 because images that we disposed of were not complete. Baseline characteristics of the 397 enrolled subjects are shown in Table 1. Briefly, the total population of our study had a median age of 49.5 years, a median smoking history of 30 pack-years, a median last CD4 count of 584 cells per microliter, and a median CD4 nadir count of 168 cells per microliter;90\% of subjects had

\begin{tabular}{|c|c|c|c|}
\hline Baseline Characteristics & Total Population $(\mathrm{N}=397)$ & No Vertebral Fracture $(\mathrm{N}=351)$ & Vertebral Fracture $(\mathrm{N}=46)$ \\
\hline Median age (IQR), yrs & $49.5(46.1-53.7)$ & $49.2(45.9-53.2)$ & $51.6(47.4-54.5)$ \\
\hline Median BMI (IQR), kg/m² & $22.4(20.2-24.7)$ & $22.5(20.1-24.7)$ & $22(20.8-24.8)$ \\
\hline BMI , 18.5 kg/m 22, n (\%) & $36(9)$ & $30(9)$ & $6(13)$ \\
\hline Median CD4 count (IQR), cells/mL & $584(416-763)$ & $574(424-760)$ & $640(383-848)$ \\
\hline Median duration of known HIV-infection (IQR), yrs & $17.7(11-22.6)$ & $17.7(10.8-22.3)$ & $17.8(12.5-23.4)$ \\
\hline Median duration of ART (IQR), yrs & $13.8(7.1-15.9)$ & $13.8(6.8-16.0)$ & $13.3(8.1-15.7)$ \\
\hline Median duration of TDF Treatment (IQR), mo & $37.0(4.2-60.5)$ & $37.0(4.3-60.3)$ & $38.8(2-71.3)$ \\
\hline Last viral load ,50 copies/mL, n (\%) & $358(90)$ & $321(91)$ & $37(80)$ \\
\hline Last viral load, 200 copies/mL, $\quad \mathrm{n}(\%)$ & $382(96)$ & $341(97)$ & $41(89)$ \\
\hline Smoking $\$ 40$ pack-years, n (\%) & $103(26)$ & $83(24)$ & $20(43)$ \\
\hline Cannabis inhalation, $\mathrm{n}(\%)$ & $143(36)$ & $126(36)$ & $17(37)$ \\
\hline IVDU, n (\%) & $115(29)$ & $100(29)$ & $15(33)$ \\
\hline Chronic alcohol intoxication, $\mathrm{n}(\%)$ & $79(20)$ & $74(21)$ & $5(11)$ \\
\hline History of AIDS, n (\%) & $109(27)$ & $97(28)$ & $12(26)$ \\
\hline
\end{tabular}

IVDU, intravenous drug users. 
a viral load below 50 copies per milliliter. The last fully visible vertebra on LDCT reconstruction was T10 for 6 subjects $(1.5 \%$ of total CT), T11 for 25 subjects (6\%), T12 for 102 subjects (26\%), L1 for 177 subjects (45\%), L2 for 86 subjects (22\%), and L4 for 1 subject. Forty-six (11.6\%) subjects had at least 1 visible fracture, and the total number of fractures was 84 . Twenty-seven subjects had 1 fracture, 10 had 2 fractures, and 9 had 3 or more fractures. No fractures were seen above T3. Two fractures were described as grade 3, 11 fractures were described as grade 2, and the 71 other fractures were described as grade 1. Fifty-seven fractures were wedge, and 27 fractures were biconcave. Details of fracture shape and location are shown in Table 2.

TABLE 2. Description of the 46 Subjects With Vertebral Fractures (Location and Shape)

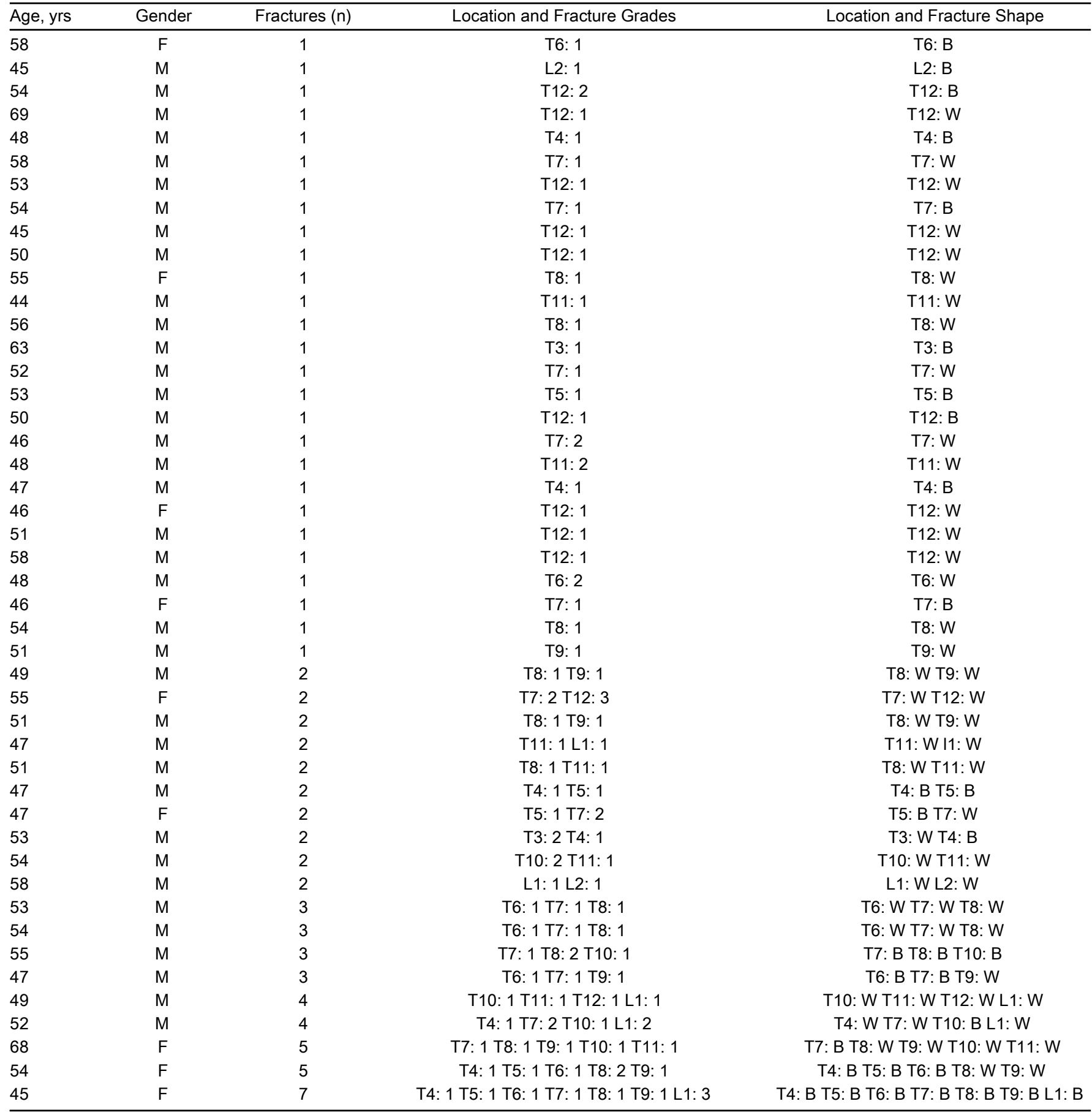

B, biconcave shape; Female; M, male; L, lumbar vertebra; Tțoracic vertebra; Wwedge shape. 
We found in "univariate" analysis that age $\$ 45$ years (in comparison with the 40-44 years reference group) and smoking 40 pack-years or more were associated with an increased risk of having at least 1 vertebral fracture (Table 3). HIV viral load ,200 copies per milliliter was associated with a lower risk. Gender, TDF (whether cumulative duration of treatment or included in the actual ART treatment),duration of ART, history of cannabis inhalation, intravenous drug use, nadir or last CD4 cell count, and history of AIDS were not associated with the outcome. HCV coinfection and alcohol intoxication met criteria for inclusion in the final model $(P$, 0.20 ). In the multivariate model, only smoking $\$ 40$ packyears was associated with an increased risk of vertebral fracture, while HIV viral load ,200 copies per milliliter was protective. In this final model, HCV coinfection and alcohol intoxication were not associated with the outcome.

\section{DISCUSSION}

In this cross-sectional multicentric study,which evaluated vertebral fractures on chest LDCT in a cohort of HIVinfected smokers or recently quitted smokers of at least 40 years of age, a CD4 nadir level ,350 cells per microliter, and a good ART coverage, we found that a substantial proportion of subjects had vertebral fractures $(11.6 \%)$.

TABLE 3. Univariate and Multivariate Analysis of Factors Associated With at Least 1 Vertebral Fracture

\begin{tabular}{|c|c|c|c|c|}
\hline \multirow[b]{2}{*}{ Variable } & \multicolumn{2}{|c|}{ Univariate Analysis } & \multicolumn{2}{|c|}{ Multivariate Analysis } \\
\hline & OR $(95 \% \mathrm{Cl})$ & $P$ & OR $(95 \% \mathrm{Cl})$ & $\mathrm{P}$ \\
\hline Gender (woman) & $1.2(0.6$ to 2.7$)$ & 0.57 & & \\
\hline \multicolumn{5}{|l|}{ Age, yrs } \\
\hline $40-44$ & Reference & & Reference & 0.29 \\
\hline $45-49$ & $4.4(1.0$ to 19.9$)$ & 0.05 & $3.8(0.8$ to 17.5$)$ & 0.09 \\
\hline $50-54$ & 6.3 (1.4 to 27.9$)$ & 0.02 & $4.4(0.9$ to 20.2$)$ & 0.06 \\
\hline$\$ 55$ & $5.8(1.2$ to 27.8$)$ & 0.03 & $3.4(0.7$ to 16.9$)$ & 0.14 \\
\hline $\begin{array}{l}\text { Smoking } \\
\qquad \text { (\$40 pack-years) }\end{array}$ & $2.5(1.3$ to 4.7$)$ &, 0.01 & $2.5(1.2$ to 5.0$)$ & 0.01 \\
\hline $\begin{array}{l}\text { History of cannabis } \\
\text { inhalation }\end{array}$ & $1.0(0.5$ to 2.0$)$ & 0.90 & & \\
\hline Low BMI , $18.5 \mathrm{~kg} / \mathrm{m} \quad 2$ & $1.6(0.6$ to 4.1$)$ & 0.33 & & \\
\hline Alcohol intoxication & $0.5(0.2$ to 1.2$)$ & 0.11 & $0.4(0.1$ to 1.1$)$ & 0.08 \\
\hline $\begin{array}{l}\text { ART duration } \\
\quad \text { (per month increase) }\end{array}$ & $1.0(1.0$ to 1.1$)$ & 0.72 & & \\
\hline $\mathrm{HCV}$ coinfection & $1.7(0.9$ to 3.2$)$ & 0.08 & $1.7(0.9$ to 3.4$)$ & 0.10 \\
\hline IVDU & $1.2(0.6$ to 2.3$)$ & 0.57 & & \\
\hline TDF use (actual) & $0.8(0.4$ to 1.4$)$ & 0.41 & & \\
\hline $\begin{array}{l}\text { Cumulative use of TDF } \\
\text { (per month longer) }\end{array}$ & $1.1(0.7$ to 1.8$)$ & 0.67 & & \\
\hline $\begin{array}{l}\text { Nadir CD4 T ,200 } \\
\text { cells/mL }\end{array}$ & 1.1 (0.6 to 2.2$)$ & 0.68 & & \\
\hline $\begin{array}{l}\text { CD4 cells } \\
\quad(\text { per } 100 / \mathrm{mL} \text { increase })\end{array}$ & $1.0(0.9$ to 1.2$)$ & 0.48 & & \\
\hline History of AIDS & $0.9(0.5$ to 1.9$)$ & 0.82 & & \\
\hline $\begin{array}{l}\text { HIV viral load }, 200 \\
\text { copies/mL }\end{array}$ & $0.2(0.1$ to 0.7$)$ & 0.01 & $0.3(0.1$ to 0.9$)$ & 0.03 \\
\hline
\end{tabular}

IVDU, intravenous drug users; OR, odds ratio.
A similar study from the NELSON group enrolled 1140 male non-HIV-infected ever smokers at risk for lung cancer. ${ }^{23}$ Vertebral spinal reconstructed sagittal planes obtained from chest axial native acquisitions of chest LDCT performed for lung cancer screening in this population were read, and vertebral fractures were graded according to Genant semiquantitative method.In this study, subjects had a mean age of 62.5 years, 531 (46.6\%) had quit smoking (by definition less than 10 years before inclusion), and subjects had a median of smoking in pack-years of 38.0 (IQR, 28.049.5). One hundred subjects $(8.8 \%)$ had at least 1 vertebral fracture. We found a higher prevalence of vertebral fractures in our study than the investigators in the NELSON study, despite lower median age and lower pack-years of smoking in our population, highlighting the fact that even relative young smoking HIV-infected subjects have substantial clinically significant osteoporosis if these fractures were indeed related to bone fragility as suspected.

Our sample is probably only representative of the French HIV-smoking population. Thus, the vertebral fracture rate in our study is probably higher than the rate we would have encountered if the studied population had been a sample of the French HIV-population. Indeed, our inclusion criteria, particularly the smoking and the nadir CD4,350 cells per microliter criteria, have induced selection of high-risk subjects for osteoporosis, as shown by our subjects' important smoking history, the proportion of HCV-infected, ${ }^{27}$ and the long known duration of HIV-infection. Other variables, though, such as gender, age, antiretroviral response, and last $\mathrm{CD} 4$ value, were in similar proportions with those encountered in the HIV-infected French population. ${ }^{28}$

The number of fractures visualized in our study is probably an underestimation of the prevalent number of spinal fractures, as some fractures may be located underneath the scanned vertebras. Numbers of vertebral fractures not visualized in our study are possibly high, although most vertebral fractures in cohorts from the general population are located in the T12-L1 vertebras. In the "Rotterdam" study for instance, in which the incidence of vertebral fractures was studied in 3469 men and women older than 55 years of age by spinal radiographs obtained at baseline and after a mean follow-up of 6.3 years, T12 and L1 were the most frequent vertebras affected in both men and women, followed by $\mathrm{L} 2$ and L3 vertebral fractures. ${ }^{21}$ In other words, about $19 \%$ of all incident fractures were located at L2 or underneath. Other studies of thoracic and lumbar radiographs have confirmed the T12 and L1 predominance of vertebral fractures in different non-HIV-infected populations. ${ }^{29-31}$

We found that TDF use (whether actual or cumulative) was not associated with the presence of vertebral fracture. TDF use has been established as a cause of accelerated bone density demineralization in randomized controlled trials with sequential DXA at the hip or the spine. In the ASSERT study, ${ }^{11}$ which included antiretroviral-naive adults taking either abacavir (ABC)-lamivudine (3TC) or TDFemtricitabine (FTC) with efavirenz, BMD was significantly different in both the hip and vertebral spine (ABC-3TC group, $21.6 \%$; TDF-FTC group, $22.4 \%$; $P=0.036)$ at week 48 in comparison with BMD at study baseline. Similar results were 
found in a switch study evaluating BMD in HIV participants randomized to raltegravir and lopinavir/ritonavir compared with lopinavir/ritonavir and a 2-3 nucleoside reverse transcriptase backbone $^{17}$ and in an ACTG trial comparing ABC3TC with TDF-FTC-treated participants. ${ }^{12}$ Thus, increased changes in BMD with TDF were significant but small, and the probability of osteoporosis or incident fractures were not different according to components in these 3 studies. Moreover, bone turnover markers normalized after week 24 in one study, ${ }^{11}$ and other studies have shown that with continued ART use, BMD stabilizes over time. ${ }^{32}$ Some cohorts did not show any association with incident or prevalent fractures with TDF use. ${ }^{14,15}$ We thus believe that TDF may have a smaller impact on vertebral fracture incidence in comparison with other factors, such as smoking. Smoking was strongly associated with the presence of a fracture $(O R=2.48)$. This study and others in the general population confirm that smoking is a major modifiable predictor of bone loss, 18,19,33 and subjects should be strongly advised to quit. Indeed, smoking cessation seems to reverse mechanisms of bone demineralization (reviewed in Yoon et $\mathrm{a}^{34}$ ). In the NELSON study, for instance, vertebral fracture prevalence was higher in the persistent smoking subgroup (11.3\%) than in the subjects who had quitted $(5.8 \%$; P , $0.001) .{ }^{23}$ In our study, age was related with an increased incidence of vertebral fracture, although it did not reach statistical significance in multivariate analysisAge probably had a small impact in our cohort, as the age distribution was narrow, as shown by the small IQR of 46.1-53.7 years. A recent literature review showed that $\mathrm{HCV} / \mathrm{HIV}$ coinfection was significantly associated with a greater risk of osteoporosis and fracture than HIV monoinfection and that these coinfected subjects should be targeted for osteoporotic prevention. ${ }^{35}$ We did not find an association of hepatitis $C$ with the presence of vertebral fracture in our study possibly because of lack of power and the fact that we did not differentiate subjects with HCV replication from subjects with spontaneous or treatment-related HCV clearance. Viral load,200 copies per milliliter seemed protective, as in some studies, ${ }^{16}$ although not all, ${ }^{7}$ perhaps through reduction of chronic inflammation $^{36}$ and underscores the importance of early ART in HIV-infected subjects to prevent osteoporosis and other comorbidities.

Our study has several other limitations. Only 1 experienced radiologist, with no double lecture of images, interpreted all reconstructed spinal planes. However, we believe that the presence of fractures was properly assessed as we recruited an experienced musculoskeletal radiologist. Also, the main outcome of our study (presence of a vertebral fracture \$grade 1) was easily assessable as it was defined by a vertebral height loss of $20 \%$ or more, limiting false-positive or false-negative results. Also, all confounders were not included in the analysis, such as ethnic origin, and other variables, such as cannabis or alcohol intoxication, would have merited further quantitative assessmento better reflect risk and a possible dose effect.

In conclusion, we found that the prevalence of vertebral fractures on chest LDCT was $11.6 \%$ in a HIV-infected cohort over 40 years of age with an important history of smoking and a CD4 nadir ,350 cells per microliter. The presence of vertebral fractures on chest LDCT should be systematically evaluated by clinicians and reported by radiologists after spinal sagittal reconstruction of axial planes, as this procedure is probably highly efficient and is an opportunity to diagnose vertebral fractures in this high-risk HIV-infected population. Our study also supports global reduction of risk behaviors, such as smoking, and early ART in preventing and managing comorbidities, such as osteoporosis. In this study, based on fractures and not on a surrogate measure, long-term TDF use was not associated with fractures.

\section{ACKNOWLEDGMENTS}

The authors thank the trial participants and the coordinators, engineers, and technicians who made this study possible: Suzanne Izard, Jonathan Lalet, and Bruno Granouillac.

The ANRS EP48 HIV CHEST Study Team: Hôpital Gustave Dron de Tourcoing: Yazdanpanah Yazdan, Cheret Antoine, Ajana Faïza, Alcaraz Isabelle, Baclet Véronique, Melliez Hugues, Valette Michel, Viget Nathalie, De La Tribonniere Xavier, Huleux Thomas, Bonne Séverine, Biekre Raphaël, Pasquet Armelle, Allienne Christophe, Behra Jean Marie, Meybeck Agnès, Aissi Emmanuelle. Hôpital Avicenne de Bobigny: Abgrall Sophie, Bouchaud Olivier, Barruet Régine, Rouges François, Kandel Tania, Mechai Fréderic, Brillet Pierre-Yves, Brauner Michel. Hôpital l'Archet de Nice: Dellamonica Pierre, De Salvador Francine, Cua Eric, Leplatois Anne, Naqvi, Alissa, Durant Jacques, Ceppi Carole, Sanderson Frédéric, Rosenthal Eric, Chassang Madleen, Chevallier Patrick, Dunais Brigitte. Hôpital Pontchailloux de Rennes: Tattevin Pierre, Lena Hervé, Lentz Pierre-Axel, Michelet Christian, Arvieux Cédric, Revest Mathieu, Souala Faouzi, Chapplain Jean-Marc, Leroy Hélène, Meunier Catherine. Hôpital Ste Marguerite de Marseille: Poizot-Martin Isabelle, Faucher Olivia, Menard Amélie, Bregigeon Sylvie, Geneau de Lamarliere Perrine, Champsaur Pierre, Durieux Olivier, Cloarec Nicolas. Hôpital Hotel Dieu de Nantes: Raffi François, Allavena Clotilde, Feuillebois Nicolas, Mounoury Olivier, Bouchez Sabelline, Billaud Eric, Reliquet Véronique, Bonnet Bénédicte, Brunet Cécile, Point Patrick, Boutoille David, Morineau Le Houssine Pascale, Delemazure Anne Sophie. Hôpital Necker de Paris: Duvivier Claudine, Catherinot Emilie, Shoai Tehrani Michka, Poiree Sylvain. Hôpital Foch de Suresnes: Zucman David, Majerholc Catherine, Couderc Louis-Jean, Mellot François, Sherrer Antoine. Hôpital La Croix Rousse de Lyon: Ferry Tristan, Koffi Joseph, Boibieux André, Miailhes Patrick, Cotte Laurent, Perpoint Thomas, Lippman Joanna, Augustin Norman Claude, Biron Francois, Senechar Agathe, Ader Florence. Hôpital Tenon de Paris: Pialloux Gilles, L'yavanc Thomas, Slama Laurence, Chas Julie, Le Nagat Sophie, Khalil Antoine, Carette Marie France. Hôpital St André de Bordeaux: Bonnet Fabrice, Morlat Philippe, Lacoste Denis, Vandenhende Marie, Anne, Receveur Marie Catherine, Paccalin Francois, Caldato Sabrina, Bernard Noëlle, Hessemfar Mojgan, Pistone Thierry, Malvy Denis, Thibaut Pierre, Pertusa Marie Carmen, Cornelou Olivier, 
Laurent Francois, Mercie Patrick, Faure Isabelle, Dondia Denis, Martell Cedric, Duffau Pierre. Hôpital Carémeau de Nîmes: Mauboussin Jean Marc, Barbuat Claudine, Rouanet Isabelle, Metge Liliane. Hôpital Gui de Chauliac de Montpellier: Reynes Jacques, Le Moing Vincent, Jacquet JeanMarc, Atoui Nadine, Loriette Mickael, Morquin David, Fauchere Vincent, Favier Carine, Merle Corinne, Baillat Vincent, Da Silva Antoine, Mansouri Rachid, Psomas Christina, Bommart Sébastien, Kovacsik-Vernhet Hélène, Pujol Jean-Louis, Quantin Xavier, Hayot Maurice.

\section{REFERENCES}

1. Bliuc D, Nguyen ND, Milch VE, et al. Mortality risk associated with low-trauma osteoporotic fracture and subsequent fracture in men and women. JAMA. 2009;301:513-521.

2. Lindsay R, Silverman SL, Cooper C, et al. Risk of new vertebral fracture in the year following a fracture. JAMA. 2001;285:320-323.

3. Ensrud KE, Black DM, Harris F, et al. Correlates of kyphosis in older women. The fracture Intervention trial Research group. J Am Geriatr Soc. 1997;45:682-687.

4. Miller J, Edwards LD, Agusti A, et al. Comorbidity, systemic inflammation and outcomes in the ECLIPSE cohort. Respir Med. 2013; 107:1376-1384.

5. Sin DD, Man JP, Man SF. The risk of osteoporosis in Caucasian men and women with obstructive airways disease. Am J Med. 2003;114:10-14.

6. Adachi JD, Adami S, Gehlbach S, et al. Impact of prevalent fractures on quality of life: baseline results from the global longitudinal study of osteoporosis in women. Mayo Clin Proc. 2010;85:806-813.

7. Cazanave $C$, Dupon $M$, Lavignolle-Aurillac $V$, et al. Reduced bone mineral density in HIV-infected patients: prevalence and associated factors. AIDS. 2008;22:395-402.

8. Arnsten JH, Freeman R, Howard AA, et al. HIV infection and bone mineral density in middle-aged women. Clin Infect Dis. 2006;42: 1014-1020.

9. Prieto-Alhambra D, Guerri-Fernandez R, De Vries F, et al. HIV infection and its association with an excess risk of clinical fractures: a nationwide case-control study. J Acquir Immune Defic Syndr. 2014;66:90-95.

10. Bedimo R, Maalouf NM, Zhang S, et al. Osteoporotic fracture risk associated with cumulative exposure to tenofovir and other antiretroviral agents. AIDS. 2012;26:825-831.

11. Stellbrink HJ, Orkin C, Arribas JR, et al. Comparison of changes in bone density and turnover with abacavir-lamivudine versus tenofoviremtricitabine in HIV-infected adults: 48-week results from the ASSERT study. Clin Infect Dis. 2010;51:963-972.

12. McComsey GA, Kitch D, Daar ES, et al. Bone mineral density and fractures in antiretroviral-naive persons randomized to receive abacavirlamivudine or tenofovir disoproxil fumarate-emtricitabine along with efavirenz or atazanavir-ritonavir:Aids Clinical Trials Group A5224s, a substudy of ACTG A5202. J Infect Dis. 2011;203:1791-1801.

13. Assoumou L, Katlama C, Viard JP, et al. Changes in bone mineral density over a 2-year period in HIV-1-infected men under combined antiretroviral therapy with osteopeniaAIDS. 2013;27:2425-2430.

14. Calmy A, Fux CA, Norris R, et al. Low bone mineral density, renal dysfunction, and fracture risk in HIV infection: a cross-sectional study. J Infect Dis. 2009;200:1746-1754.

15. Yong MK, Elliott $\mathrm{JH}$, Woolley IJ, et al. Low CD4 count is associated with an increased risk of fragility fracture in HIV-infected patients. J Acquir Immune Defic Syndr. 2011;57:205-210.

16. Fausto A, Bongiovanni M, Cicconi P, et al. Potential predictive factors of osteoporosis in HIV-positive subjects. Bone. 2006;38:893-897.
17. Martin A, Moore C, Mallon PW, et al. Bone mineral density in HIV participants randomized to raltegravir and lopinavir/ritonavir compared with standard second line therapy.AIDS. 2013;27:2403-2411.

18. Romme EA, Murchison JT, Edwards LD, et al. CT-measured bone attenuation in patients with chronic obstructive pulmonary disease: relation to clinical features and outcomes. J Bone Miner Res. 2013;28: 1369-1377.

19. Maclnnis RJ, Cassar C, Nowson CA, et al. Determinants of bone density in 30- to 65-year-old women: a co-twin study. J Bone Miner Res. 2003; $18: 1650-1656$

20. El Maghraoui A, Rezqi A, Mounach A, et al. Systematic vertebral fracture assessment in asymptomatic postmenopausal women. Bone. 2013;52:176-180.

21. Van der Klift M, De Laet CE, McCloskey EV, et al. The incidence of vertebral fractures in men and women: the Rotterdam Study. J Bone Miner Res. 2002;17:1051-1056.

22. Cooper C, Atkinson EJ, O'Fallon WM, et al. Incidence of clinically diagnosed vertebral fractures: a population-based study in Rochester, Minnesota, 1985-1989. J Bone Miner Res. 1992;7:221-227.

23. de Jong WU, de Jong PA, Vliegenthart R, et al. Association of COPD and smoking status with bone density and vertebral fractures in male lung cancer screening participants. J Bone Miner Res. 2014;29: 2224-2229.

24. Huda W, Ogden KM, Khorasani MR. Converting dose-length product to effective dose at CT. Radiology. 2008;248:995-1003.

25. Genant $\mathrm{HK}, \mathrm{WuCY}$, van Kuijk C, et al. Vertebral fracture assessment using a semiquantitative technique. J Bone Miner Res. 1993;8: 1137-1148.

26. Buckens $\mathrm{CF}$, de Jong $\mathrm{PA}, \mathrm{Mol} \mathrm{C}$, et al. Intra and interobserver reliability and agreement of semiquantitative vertebral fracture assessment on chest computed tomography. PLoS One. 2013;8:e71204.

27. Roux $P$, Demoulin B, Sogni $P$, et al. Coinfection with hepatitis $C$ virus in people living with HIV: data from the ANRS-VESPA2 survey. Bull Epidemiol Hebd (Paris). 2013;26-27:314-320.

28. Dray-Spira R, Wilson d'Almeida K, Aubrière $C$, et al. Health status of people living with HIV followed at hospital in metropolitan France in 2011 and characteristics of those recently diagnosed. Results of the ANRS-VESPA2 Study. Bull Epidemiol Hebd (Paris). 2013;26-27: 285-292.

29. Ferrar L, Roux C, Felsenberg D, et al. Association between incident and baseline vertebral fractures in European women: vertebral fracture assessment in the Osteoporosis and Ultrasound Study (OPUS). Osteoporos Int. 2012;23:59-65.

30. Delmas PD, van de Langerijt L, Watts NB, et al. Underdiagnosis of vertebral fractures is a worldwide problem: the IMPACT study. J Bone Miner Res. 2005;20:557-563.

31. Grados F, Marcelli C, Dargent-Molina P, et al. Prevalence of vertebral fractures in French women older than 75 years from the EPIDOS study. Bone. 2004;34:362-367.

32. Bolland MJ, Grey A, Horne AM, et al. Stable bone mineral density over 6 years in HIV-infected men treated with highly active antiretroviral therapy (HAART). Clin Endocrinol (Oxf). 2011;76:643-648.

33. Hopper JL, Seeman E. The bone density of female twins discordant for tobacco use. N Engl J Med. 1994;330:387-392.

34. Yoon V, Maalouf NM, Sakhaee K. The effects of smoking on bone metabolism. Osteoporos Int. 2012;23:2081-2092.

35. Dong HV, Cortes YI, Shiau S, et al. Osteoporosis and fractures in HIV/hepatitis $\mathrm{C}$ virus coinfection: a systematic review and meta-analysis. AIDS. 2014;28(14):2119-2131.

36. Hileman CO, Labbato DE, Storer NJ, et al. Is bone loss linked to chronic inflammation in antiretroviral-naive HIV-infected adults? A 48-week matched cohort study. AIDS. 2014;28:1759-1767. 